\title{
Modeling of Commercial Turbofan Engine With Ice Crystal Ingestion: Follow-On
}

Philip C. E. Jorgenson, Joseph P. Veres, and Ryan Coennen

Glenn Research Center, Cleveland, Ohio 


\section{NASA STI Program . . . in Profile}

Since its founding, NASA has been dedicated to the advancement of aeronautics and space science. The NASA Scientific and Technical Information (STI) program plays a key part in helping NASA maintain this important role.

The NASA STI Program operates under the auspices of the Agency Chief Information Officer. It collects, organizes, provides for archiving, and disseminates NASA's STI. The NASA STI program provides access to the NASA Aeronautics and Space Database and its public interface, the NASA Technical Reports Server, thus providing one of the largest collections of aeronautical and space science STI in the world. Results are published in both non-NASA channels and by NASA in the NASA STI Report Series, which includes the following report types:

- TECHNICAL PUBLICATION. Reports of completed research or a major significant phase of research that present the results of NASA programs and include extensive data or theoretical analysis. Includes compilations of significant scientific and technical data and information deemed to be of continuing reference value. NASA counterpart of peer-reviewed formal professional papers but has less stringent limitations on manuscript length and extent of graphic presentations.

- TECHNICAL MEMORANDUM. Scientific and technical findings that are preliminary or of specialized interest, e.g., quick release reports, working papers, and bibliographies that contain minimal annotation. Does not contain extensive analysis.

- CONTRACTOR REPORT. Scientific and technical findings by NASA-sponsored contractors and grantees.
- CONFERENCE PUBLICATION. Collected papers from scientific and technical conferences, symposia, seminars, or other meetings sponsored or cosponsored by NASA.

- SPECIAL PUBLICATION. Scientific, technical, or historical information from NASA programs, projects, and missions, often concerned with subjects having substantial public interest.

- TECHNICAL TRANSLATION. Englishlanguage translations of foreign scientific and technical material pertinent to NASA's mission.

Specialized services also include creating custom thesauri, building customized databases, organizing and publishing research results.

For more information about the NASA STI program, see the following:

- Access the NASA STI program home page at http://www.sti.nasa.gov

- E-mail your question to help@sti.nasa.gov

- Fax your question to the NASA STI Information Desk at 443-757-5803

- Phone the NASA STI Information Desk at 443-757-5802

- Write to: STI Information Desk NASA Center for AeroSpace Information 7115 Standard Drive Hanover, MD 21076-1320 


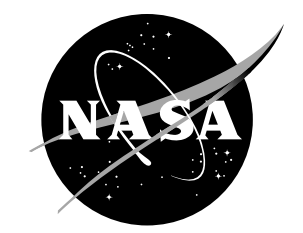

\section{Modeling of Commercial Turbofan Engine With Ice Crystal Ingestion: Follow-On}

Philip C. E. Jorgenson, Joseph P. Veres, and Ryan Coennen Glenn Research Center, Cleveland, Ohio

Prepared for the

6th Atmospheric and Space Environments Conference

sponsored by the American Institute of Aeronautics and Astronautics Atlanta, Georgia, June 16-20, 2014

National Aeronautics and

Space Administration

Glenn Research Center

Cleveland, Ohio 44135 


\section{Acknowledgments}

This work is supported by the Atmospheric Environment Safety Technology Project (AEST) in the NASA Aviation Safety Program, and is in response to the Engine Icing Technical Challenge. We would like to thank Dr. Renato Colantonio, manager of the NASA Atmospheric Environment Safety Technologies (AEST) project, under the Aviation Safety Program (ASP) for supporting this work. We would also like to acknowledge Dr. Michael Oliver, Dr. Judith Foss Van Zante, Timothy Bencic, Amy Fagan, Christopher Lynch, Bryan Rosine, Tom Griffin, Queito Thomas, Jonathan Paul Kirkegaard, Dennis Dicki, Paul Lizanich, Steve Pesek, Pamela Poljak, Kent A. Smith, and the rest of the PSL technicians and engineers that supported the test and facility development at NASA Glenn Research Center for providing the excellent test data for this engine in the unique altitude test facility with spray bars that successfully simulated ice ingestion testing. We also acknowledge the help and guidance we received from Dr. William B. Wright (Vantage Partners, LLC.) for guidance in providing the MELT code, Mr. Scott Jones at NASA Glenn Research Center in the use of the engine cycle code, and Dr. Jen-Ching Tsao (Ohio Aerospace Institute) for his insights and analyses.

Level of Review: This material has been technically reviewed by technical management.

Available from

NASA Center for Aerospace Information 7115 Standard Drive Hanover, MD 21076-1320
National Technical Information Service 5301 Shawnee Road Alexandria, VA 22312 


\title{
Modeling of Commercial Turbofan Engine With Ice Crystal Ingestion; Follow-On
}

\author{
Philip C. E. Jorgenson, Joseph P. Veres, and Ryan Coennen ${ }^{*}$ \\ National Aeronautics and Space Administration \\ Glenn Research Center \\ Cleveland, Ohio 44135
}

\begin{abstract}
The occurrence of ice accretion within commercial high bypass aircraft turbine engines has been reported under certain atmospheric conditions. Engine anomalies have taken place at high altitudes that have been attributed to ice crystal ingestion, partially melting, and ice accretion on the compression system components. The result was degraded engine performance, and one or more of the following: loss of thrust control (roll back), compressor surge or stall, and flameout of the combustor. As ice crystals are ingested into the fan and low pressure compression system, the increase in air temperature causes a portion of the ice crystals to melt. It is hypothesized that this allows the ice-water mixture to cover the metal surfaces of the compressor stationary components which leads to ice accretion through evaporative cooling. Ice accretion causes a blockage which subsequently results in the deterioration in performance of the compressor and engine. The focus of this research is to apply an engine icing computational tool to simulate the flow through a turbofan engine and assess the risk of ice accretion. The tool is comprised of an engine system thermodynamic cycle code, a compressor flow analysis code, and an ice particle melt code that has the capability of determining the rate of sublimation, melting, and evaporation through the compressor flow path, without modeling the actual ice accretion. A commercial turbofan engine which has previously experienced icing events during operation in a high altitude ice crystal environment has been tested in the Propulsion Systems Laboratory (PSL) altitude test facility at NASA Glenn Research Center. The PSL has the capability to produce a continuous ice cloud which is ingested by the engine during operation over a range of altitude conditions. The PSL test results confirmed that there was ice accretion in the engine due to ice crystal ingestion, at the same simulated altitude operating conditions as experienced previously in flight. The computational tool was utilized to help guide a portion of the PSL testing, and was used to predict ice accretion could also occur at significantly lower altitudes. The predictions were qualitatively verified by subsequent testing of the engine in the PSL. In a previous study, analysis of select PSL test data points helped to calibrate the engine icing computational tool to assess the risk of ice accretion. This current study is a continuation of that data analysis effort. The study focused on tracking the variations in wet bulb temperature and ice particle melt ratio through the engine core flow path. The results from this study have identified trends, while also identifying gaps in understanding as to how the local wet bulb temperature and melt ratio affects the risk of ice accretion and subsequent engine behavior.
\end{abstract}

*NASA Glenn Research Center, student intern from Kent State University. 


\section{Introduction}

THERE have been numerous reported engine icing events ${ }^{1}$ that have occurred on commercial airlines (Figure 1) during flight through clouds with high ice water content. These events have been attributed to ice crystal ingestion and subsequent ice accretion (hereafter referred to as ice accretion) and are thought to occur on the stationary parts in the region of the low pressure compressor. The total number of engine icing events per year appears to be increasing since $2002 .^{2}$

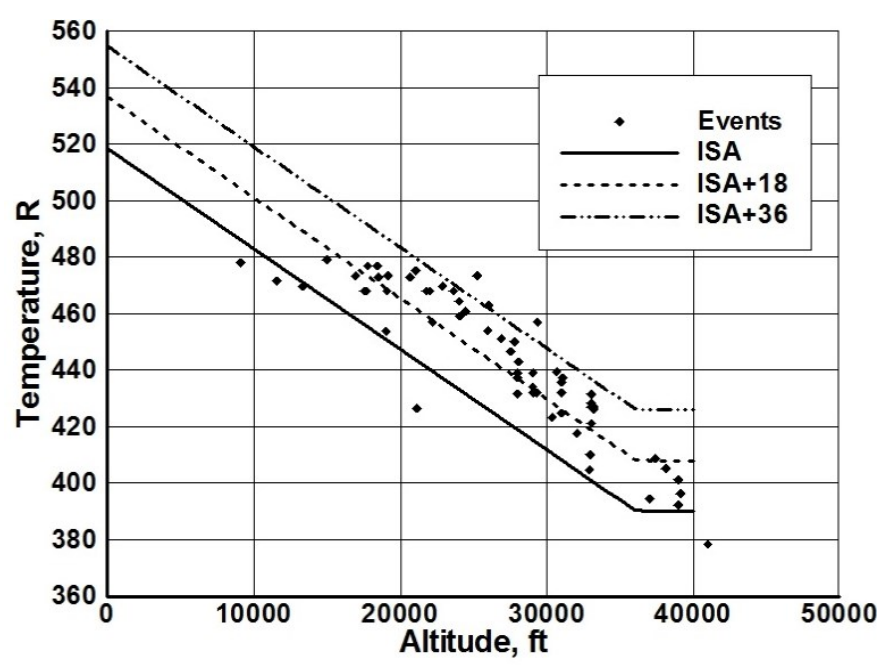

Figure 1: Reported engine icing events. The engine events occurred at altitudes between $10 \mathrm{~K}$ and $40 \mathrm{~K}$ feet and at temperatures between ISA and ISA+36 R.

A computational tool ${ }^{3,4}$ has been developed with the capability to analyze the performance of a turbine engine as it ingests ice crystals while flying through an ice cloud at altitude conditions. The tool can be used to evaluate the susceptibility of turbine engines to ice accretion. The tool has an engine system thermodynamic cycle code, a compressor flow analysis code, a fluid properties code, and an ice particle melt code. The mixed fidelity computational tool provides details of the flow conditions within each blade row of the fan and low pressure compression system (LPC) during operation in the engine system environment. Ice accretion in the LPC reduces the available aerodynamic area and deteriorates the performance of the compressor, and consequently on the overall performance of the engine. In this paper the performance loss of the compressor due to accretion is not addressed, since the focus is on the risk of ice accretion. However, ice accretion can result in uncommanded reduction in thrust, compressor surge, and combustor flameout ${ }^{1}$.

In this study a turbofan engine is modeled at the altitude, vehicle flight Mach number, ambient temperature and engine thrust level where it has been known to experience an icing event that was attributed to ice accretion in the low pressure compressor. Note that this engine model is no longer in service, and has been replaced with a new version which does not experience any icing events. The original engine that did experience icing events was procured, installed, and tested in the Propulsion Systems Laboratory (PSL) altitude test facility at NASA Glenn Research Center in the month of February, 2013. The test facility is equipped with water spray bars capable of producing an ice crystal cloud that simulates the ice clouds at high altitudes. The engine was tested over a range of conditions, including the flight altitudes, Mach number, and fan speeds where it had experienced uncommanded thrust reduction due to ice accretion in the low pressure compressor stator region. During testing in the PSL at simulated altitude conditions, engine icing event was duplicated successfully at operating points where it previously experienced an icing event during flight. The purpose of this research is to apply an engine icing computational tool to simulate the flow through the turbofan engine in order to determine the wet bulb temperature and ice particle melt ratio through the LPC flow path, at the selected data points that were obtained in the PSL. The computational tool was utilized to increase understanding of the flow field within the low pressure compressor at numerous operating conditions that resulted in ice accretion. During the PSL engine testing, the computational tool was used to suggest additional operating points at lower altitudes where the there is a risk of ice accretion, other than the altitudes where there it experienced icing events in flight. These additional operating conditions were then tested in PSL and engine ice accretion was encountered at operating conditions close to those predicted with the modeling tool. 


\section{Engine / Compressor Modeling Codes}

The computational tool that has been utilized to analyze the engine at the selected test points in this study is the customer deck (CD) engine thermodynamic cycle code that was obtained from the engine manufacturer, and the mean line compressor flow analysis code 5 . The code includes a fluid properties model to account for supplemental water vapor in the air. Additionally, the computational tool incorporates a code named MELT to model the melting of ice particles. This code leverages capabilities from the LEWICE2D code. ${ }^{6,7}$ These codes have been coupled together such that they exchange boundary conditions at each iteration. The compressor analysis code computes the detailed blade row by blade row flow conditions, as well as the overall compressor performance. The MELT code has been developed to compute the melting rate of ice crystals, as they pass through the engine inlet, fan and low pressure compressor blade rows. The models for sublimation, melting, and evaporation in the MELT code have been adapted from the LEWICE2D code; however, there are no models for ice accretion, particle breakup, shedding, or erosion in MELT. The compressor code, $\mathrm{COMDES}^{5}$, and MELT have been coupled to exchange boundary conditions at the blade leading and trailing edges. The compressor code has a model to calculate the effects of water vapor on the fluid properties of the air - water vapor mixture based on the mole fraction of air to water vapor. The local relative humidity is computed through each component of the inlet-fan-LPC, taking the sublimation, melting, and evaporation into consideration, as well as the local static temperature of the air. The resulting performance of the compressor is computed based on air fluid properties with humidity.

A. Aerothermodynamic Simulation of the Engine System; Customer Deck and Compressor Flow Model

The customer deck (CD), that models the aerothermodynamic performance of the turbofan engine, was obtained from the engine manufacturer. The CD code provides the overall component-level performance and flow conditions, pressures, and temperatures, as illustrated in Figure 2. The fan is split into two distinct regions, the fan tip which models the flow through the bypass, and the fan core, which includes the low pressure compressor (supercharger). The CD system modeling code is comprised of component characteristic maps for each major engine component, and does not have the fidelity to provide the flow conditions within the stages and blade rows. Therefore a mean line compressor flow code, COMDES, was utilized to provide the flow conditions at a higher fidelity within each blade row of the multi-stage fan-core and low pressure compressor.

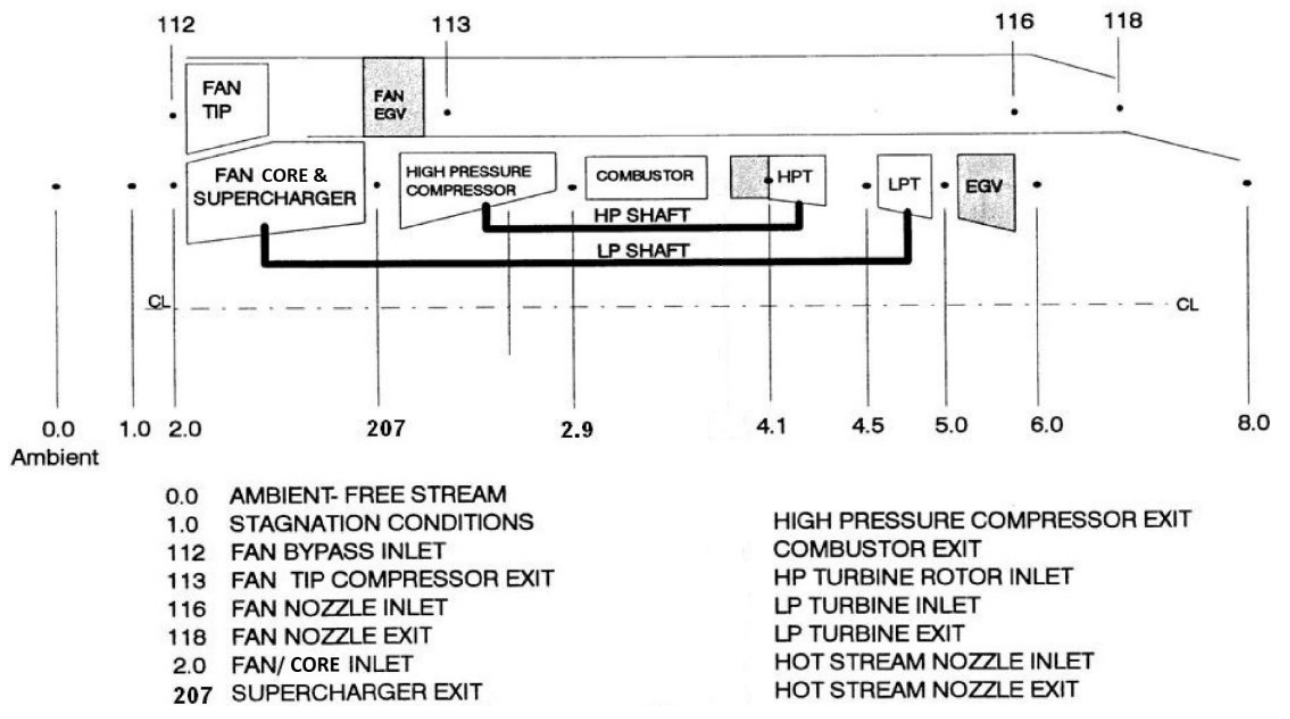

Figure 2: The engine block diagram of the two spool turbofan engine, as modeled in the Customer Deck (CD).

The inputs provided to the CD system modeling code are the altitude, flight Mach number, fan physical rotational speed, and the air static temperature. The model results include the aerothermodynamic performance of each major engine component, as described in Figure 2, including the bypass ratio. The main purpose of the CD engine system model was to provide the bypass ratio and thus, the air mass flow into the engine core.

The COMDES and the CD system codes were utilized such that the boundary conditions from the $\mathrm{CD}$ at each operating point were passed as inlet boundary conditions to the compressor flow analysis code. A spreadsheet was created which 
facilitates a rapid means of providing the input into the $\mathrm{CD}$ code, code execution, passing the boundary conditions (BCs) to COMDES, and execution of it as well. The block diagram in Figure 3 illustrates the process by which the boundary condition data is transferred between the CD system model and the mean line flow analysis code. Note that there is no accretion model in the current simulation, therefore a two way exchange of BCs between the CD and COMDES is not required. The codes are outlined with the rectangular shaped border, while the boundary condition information passed between the codes have borders with rounded corners.

\section{Computational Process}

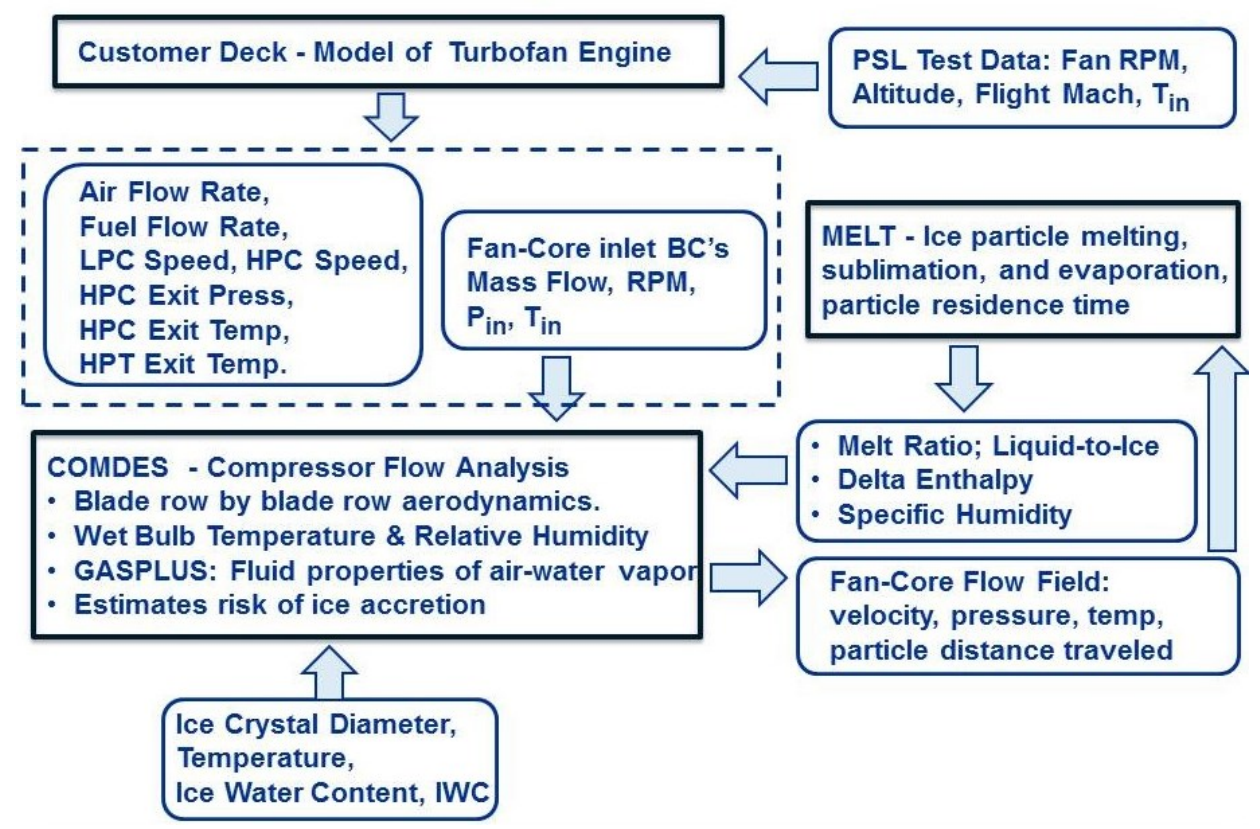

Figure 3: The CD engine system model, COMDES ${ }^{5}$ compressor flow model and MELT computer model boundary exchange strategy for the fan-core and LPC. GASPLUS ${ }^{8}$ is the fluids properties code. The fan-core and LPC performance is computed with the COMDES code, and the MELT code.

The CD was executed first and provided the calculated air mass flow rate into the engine core, as well as the shaft speed (RPM), inlet total temperature and pressure for a given engine operating point. The next step in the process was to execute the compressor analysis code to obtain the detailed blade row by blade row flow analysis of the fan-core and LPC in the engine system environment, including the local pressure and temperature between each rotor and stator blade rows. Additional parameters that were calculated by the compressor model include the relative humidity, wet bulb temperature, and the ice particle melt ratio, which is the local value of the liquid water to the total water ratio (ice + water), referred to in this study as the ice particle melt ratio.

The COMDES flow code computes the velocity, pressure, temperature, and flow angles at the leading edge and trailing edge of each blade row, at the hub, mean, and tip sections. The mean line compressor flow analysis code has been modified to include the effects of relative humidity on the fluid properties of air and water vapor mixture, and the subsequent effects on compressor performance. The capability to calculate the local relative humidity in each blade row is based on the initial value of specific humidity (mass of water/mass of air) at the engine inlet, as well as the sublimation and evaporation of the particles through the flow path. The two key parameters which have been identified as indicators of the risk of ice accretion are computed at each flow station: the local wet-bulb temperature and the ice particle melt ratio. If the limiting values of these key parameters are met, there is a risk that ice will accrete on the surfaces of the compressor at that station. With these parameters as the precursors to the risk of ice accretion, the blade row within the compression system can be identified that is likely to experience ice buildup at a particular engine operating condition. In this engine, the location where ice accretes is suspected to be in the region of the exit guide vane tandem stators, later referred to as the "Targeted Area." 
The ice particle melting and evaporation model, MELT, computes the local ice particle melt ratio and calculates the change of phase of an ice particle as it passes through the various components of the engine, starting at the engine inlet and through the fan and low pressure compressor blades and stator vanes. The ice particle residence times through each component are estimated in the MELT routine and are based on the velocities at the inlet and exit of the component and the distance the particle travels. The components are the engine inlet, each rotor and stator blade, support strut, and the axial gaps between the rotors, stators and the struts. The specific humidity, the ice water content (IWC), and particle diameter are specified at the inlet to the engine. Since there is no particle breakup model in the MELT code, the value for ice particle diameter in this study is assumed to be $5 \mu \mathrm{m}$, while the ice water content (IWC) is specified from the test data taken in the PSL. After the flow conditions through the blade rows have been calculated by COMDES, the static temperatures, pressures, and velocities are passed to MELT to determine the rate of melting, sublimation, and evaporation, and thus, the local ice particle melt ratio in each blade row. The calculations for sublimation, melting, and evaporation take into consideration the local static temperatures, pressures, and residence times as they traverse through the engine inlet, the fan-core and low pressure compressor blade passages and gaps at the mid span location, the gooseneck duct and the support strut.

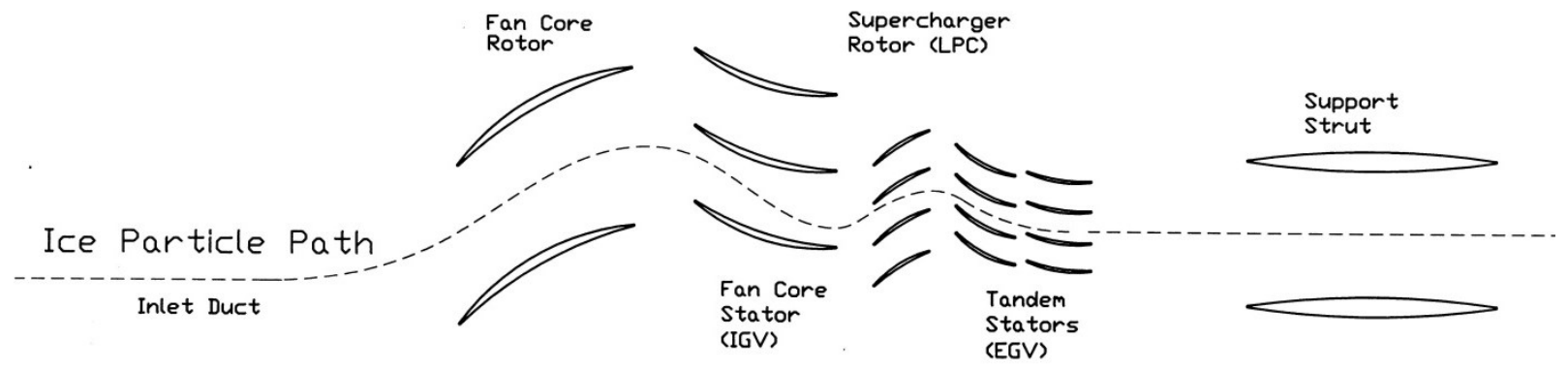

Figure 4: Ice particle path through the inlet, fan-core and supercharger stage, and support strut. The distance traveled by the particle is estimated from the mid-span rotor and stator mean camber chord length.

Figure 4 shows a simplified illustration of the ice particle path through the rotor blades in the relative frame of reference, while the path through the stator vanes is in the absolute frame of reference. The calculations of ice sublimation, melt, and evaporation are performed from the leading to the trailing edge of each rotor and stator, as well as through the axial gap between the blades, as a function of velocity and distance traveled. The distances traveled are assumed to be equal to the chord length of each rotor and stator, as well as the gap between rotor and stator. The amount of water due to sublimation and evaporation is added to the local value of specific humidity, thus having an effect on the local relative humidity, and likewise on the local wet-bulb temperature calculation in the compressor code.

\section{B. Ice Accretion Risk Criteria}

The targeted area in this engine where ice accretion is suspected to initiate has been identified by the manufacturer as the tandem stator (EGV) region. Based on preliminary experimental findings of ice accretion on an airfoil at the National Research Council of Canada (NRCC), ${ }^{9,10}$ in order for ice accretion to occur, the wet-bulb temperature was set to a value several degrees Celsius above, or below the freezing temperature of water. In those experiments, the other key parameter for ice accretion was found to be the local ice particle melt ratio. These two parameters are considered to be the necessary conditions which must be met simultaneously at the same location in the compressor, in order for there to be a risk of ice accretion. Based on observations that were made from the laboratory test data, ${ }^{9}$ an ice particle melt ratio in the vicinity of $10 \%$ or greater was considered a requirement in order for accretion to occur. However, in this study, the values for these two parameters were determined in the targeted region from the flow analysis of the fan and LPC at the test data points where this engine experienced ice accretion during PSL testing. The results of the analyses provided the range of values for these parameters. For each data point taken in the PSL, the wet bulb temperatures and the ice particle melt ratio were calculated for this engine. Since the wet-bulb temperature and the ice particle melt ratio both change through each blade row of the fan-core and LPC, the focus of the study was to determine these values in the "Targeted Area." It is recognized that other parameters such as the heat transfer rate through the blades and flow path walls need to be considered as well, but are not included in the current version of the compressor flow analysis code. It is assumed in this study that accretion due to ice crystals does not occur on 
compressor rotors. Therefore the assumption is that accretion can only occur on the stator vanes and flow path walls, including downstream of the last stator of the LPC e.g., the "Targeted Area."

\section{Icing Risk Analysis of a Turbofan Engine with Ice Crystal Cloud Ingestion}

\section{A. Ice Crystal Particle vs. Air Temperature through the Engine Inlet in a Direct Connect Facility}

The computational flow modeling starts at the direct connect duct flange of the PSL test facility. The engine tested was connected to the PSL test facility in a "direct connect" manner. The pipe supplying the air flow is connected to the engine flange, as illustrated in Figure 5. In this sense, the engine does not have a typical flight inlet nacelle, but does feature a section of pipe that acts as an "inlet" which diffuses the flow ahead of the fan face. The PSL test facility has been calibrated over a limited range of altitudes and temperatures to provide known flow conditions and glaciated ice crystals at the inlet of this inlet duct. The computer flow analysis in this study begins at the entrance of this duct, and continues through the fan core, LPC, and support strut.

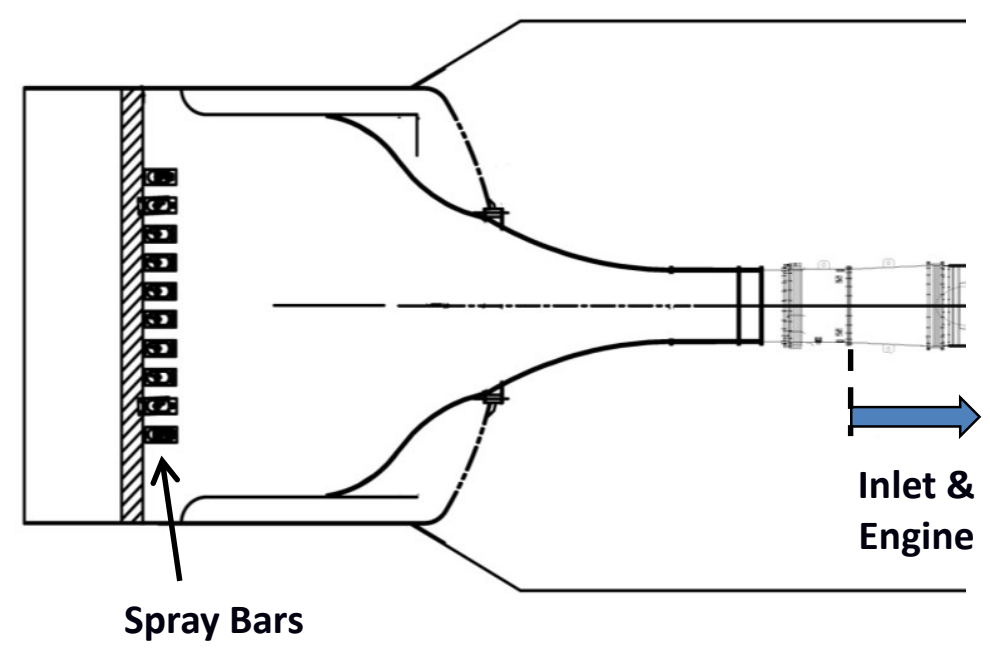

Figure 5: Inlet duct in the PSL test facility connects directly to the engine inlet flange.

The "flight" Mach number that is being simulated in the tunnel is utilized to calculate the relation between the static and total temperature at the inlet of the inlet duct. At the inlet, the temperature of the ice crystals is assumed to be equal to the static temperature of the air at the simulated flight Mach number. However, because of a moderately high flight Mach number, the total temperature of the air is higher. As the air is diffused through the subsonic inlet, the static temperature of the air rises before reaching the fan leading edge, and the temperature of the ice particle likewise increases. At high altitude operating conditions the temperature of the ice particles through the engine inlet is typically well below freezing, until the particles are inside the fan-core and LPC, where the temperature rises rapidly, due to the energy addition by the rotors ${ }^{3}$.

Although the computer code (COMDES) models the air flow and ice crystal physics through the inlet duct portion of the engine, the subsequent figures will focus on illustrating the flow conditions of wet bulb temperature and ice particle melt ratio in the fan-core and LPC, since those are the regions where there may be a risk of accretion due to ice crystals.

\section{B. Icing Risk Analysis of the Fan Core and Low Pressure Compressor.}

In order to perform the aerothermodynamic flow analysis of the engine that was tested in the PSL, it was necessary to obtain the detailed geometry of the low pressure compressor (LPC) such that the flow conditions between each blade row could be computed with the mean line compressor flow code. Figure 6 illustrates a notional representation of the fan and low pressure compressor cross section of the turbofan engine tested in the PSL. Note that there is a notional streamline that is utilized in the compressor flow code that represents the cutwater between the air flow that enters the fan bypass duct, and the flow that enters the core. This streamline separates the outer bypass flow from the core flow and is utilized in the mean line model as the outer flow path wall of the fan-core. This engine features a heated spinner 
and a heated fan core stator row (inlet guide vane) shown in Figure 6. The tandem stators in the low pressure compressor stage (exit guide vanes - EGV) are also shown in the figure.

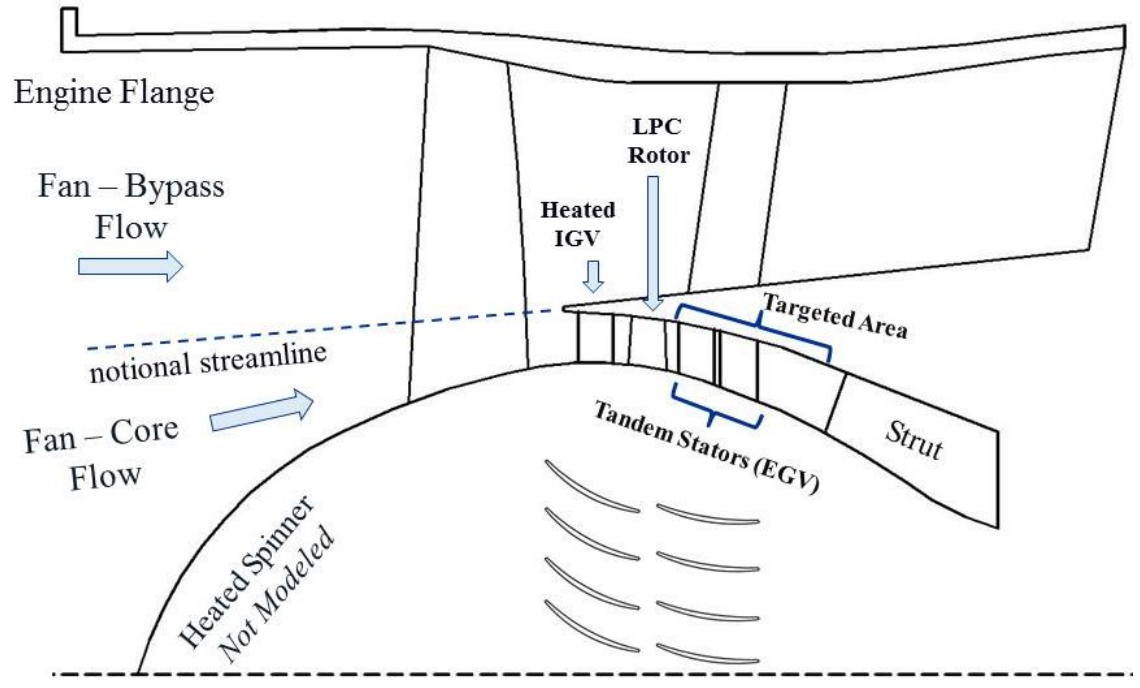

Figure 6: Schematic of the fan and low pressure compressor portion of the engine tested in the PSL with ice crystal ingestion, illustration the tandem stators of the EGV, and the Targeted Area.

During the testing with the ice cloud on, the engine experienced numerous uncommanded thrust reductions, presumably due to ice accretion in the "Targeted Area." However, there were also data points where the engine did not experience an icing event even when the ice water content was increased. From the test data that was generated in PSL, all test data points with ice ingestion were analyzed utilizing the computer models described in Section I (Figure 3 ). An engine icing event caused by ice accretion was defined by the test engineers as the point where the engine thrust was observed to decrease to a value of approximately $93 \%$ of the thrust load value before the ice cloud initiation. The assumption was that at these events the engine experienced large enough levels of accretion such that engine roll back would follow if the testing with the ice cloud on had been continued. This definition of an icing event was used to reduce the amount of ice accretion, in order to protect the engine from subsequent potential damage of the high pressure compressor due to ice shedding from the LPC.

This analysis considers the source of liquid water due to the partial melting of the ice particle by the air through the heat of compression. Other sources of liquid water may be present in the flow field as well that are currently not accounted for in the computer modeling. This engine has a heated spinner and heated inlet guide vane (stator) which are both potentially additional sources of liquid water. The CD engine system model analysis does take into consideration the addition of compressor discharge air that heats the stator row (inlet guide vane) as shown in Figure 6. This small amount of compressor discharge air is mixed with the core flow, resulting in a slight increase in the bulk temperature of the air entering the core, and therefore has an effect on the inlet temperature utilized in the compressor flow analysis.

The analysis tool was executed at all PSL engine test data points that were recorded, including data points that produced both engine icing events as well as points where no engine icing events were encountered. The altitude, vehicle Mach number, fan rotational speed, and ambient temperature were specified in the engine CD model. For this analysis, the ice water content values prescribed during the PSL testing were used in the flow analysis computer model. Since there is currently no ice particle break up model in the compressor flow analysis code, the ice particle size utilized in this study was set at $5 \mu \mathrm{m}$. This particle size was found to be the most susceptible to providing a non-zero ice particle melt ratio in the "Targeted Area" of the LPC during the operating points which resulted in an engine icing event. The typical ice water content (IWC) for all test points was less than $3 \mathrm{~g} / \mathrm{m}^{3}$. The computer flow analysis shows that for these test points, the amount of liquid water due to the heating by the air contributes to the total amount of melted water in the flow path. However, other sources of liquid water were not estimated by this model. The flow analysis of the fan-core and low pressure compressor was computed at the specific engine operating condition taken from the test data just prior to the ice cloud initiation. All the engine test data points were analyzed with the CD engine 
system model and the compressor flow analysis code. The analyses performed determined the wet bulb temperature, based on both the local static and total temperatures, and melt ratio in the core flow path, specifically in the tandem stator region, for all the test data points taken in the PSL. The purpose was to quantify these two parameters at three different types of engine events observed on the test stand, specifically, imminent, gradual, and no engine icing event conditions. The imminent and gradual engine icing event data point categories delineate between the wide variations in the time it took for the engine icing event to occur. In this study the imminent events were likely caused by a faster rate of ice accretion, while the gradual engine events were likely caused by a slower rate of ice accretion, presumably leading to an engine roll back. The no engine icing event could have ice accretion, but engine roll back was not expected to occur.

Test Data Points Resulting in an Imminent Engine Icing Event.

At the data points where significant ice accretion is suspected to have occurred, the rotational speed of the low and high speed spools and level of relative thrust decreased from their nominal values. It was determined that the engine icing event was imminent (fast) when a pre-specified percent decrease of thrust was reached, as stated previously.

The existence of liquid water in the air appears to be an important factor in causing ice accretion. As previously mentioned, this analysis addressed the source of liquid water from melting of the ice particle due to warm air caused by the heat of compression. Other sources of heat that are not modeled in this analysis that could potentially add liquid water to the air are the heated spinner and the heated inlet guide vane, which is an anti-ice feature.

The stream wise distribution of local static temperature along the flow path and the ice particle residence time in the rotor blades, stator vanes, and gaps are two important parameters that determine the ice particle melt ratio due to heating by the air. Figures $7 \mathrm{a}$ and $7 \mathrm{~b}$ show the flow analysis results of the test data points that resulted in an imminent engine icing event. The figures illustrate the stream wise distribution of the wet bulb temperature based on the calculated total and static temperatures (Figures $7 \mathrm{a}, 7 \mathrm{~b}$ respectively), as well as the ice particle percent melt ratio. The targeted area where ice accretion is suspected to initiate is the tandem stator (EGV) region. At the data points where engine icing events were imminent, illustrated in Figure 7a, 7b, the wet bulb temperatures based on the local value of total temperature in the low pressure compressor Targeted Area was in a narrow range of $7 \mathrm{R}$, with an average value being $13 \mathrm{R}$ above freezing. The wet bulb temperature based on the calculated local static temperature had a range of $9 \mathrm{R}$, with an average value of $2 \mathrm{R}$ above freezing. The local static temperature affects the melt ratio of the ice particle. The existence and the percentage of liquid water due to heating by the air appeared to have an effect on the rate of ice accretion. In the imminent icing event cases, the ice particle melt ratio due to heating by the air at the tandem stator trailing edge was an average of $12 \%$, with a range of $2 \%-40 \%$. Further analyses, including multidisciplinary simulation of more detailed test data, are needed in order to better understand the possible effect of all sources of heat in this engine on the ice crystal melting process.
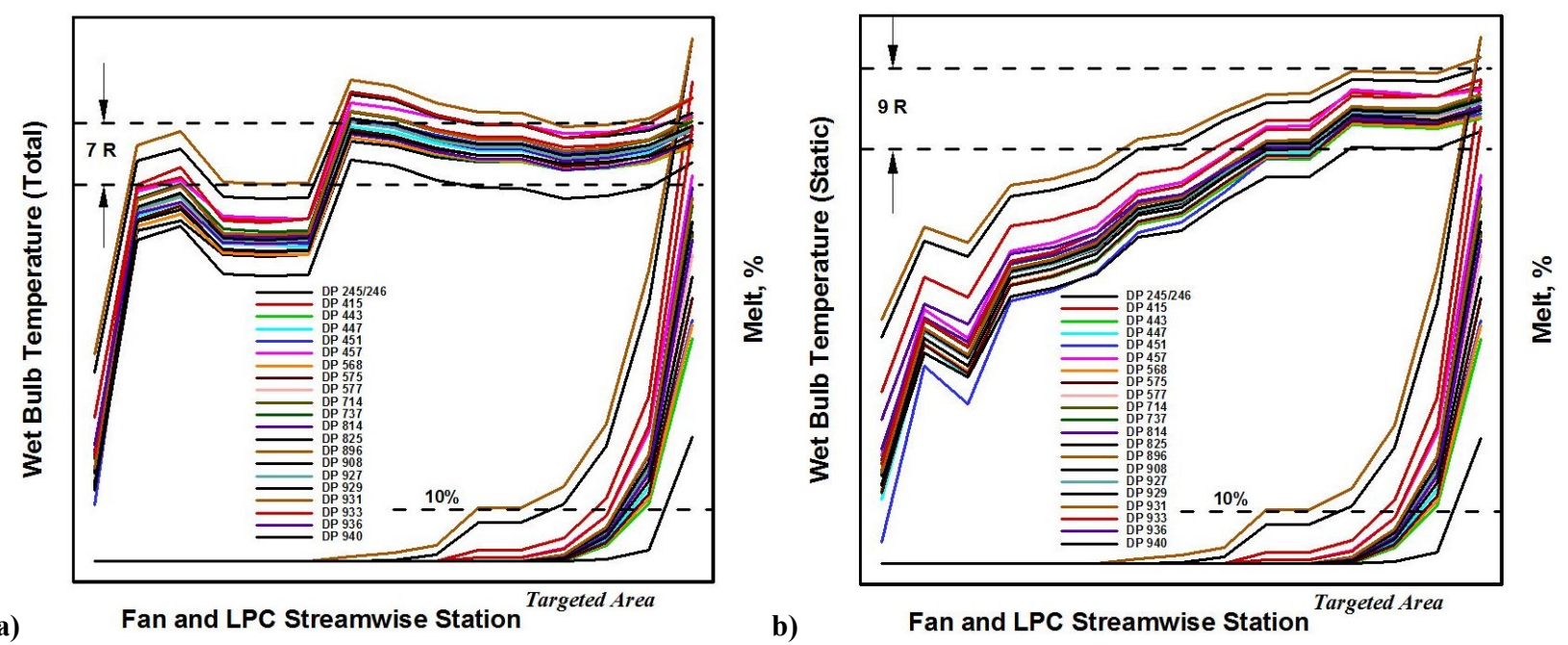

Figure 7: Flow analysis of the fan-core and LPC stage at the test data points which resulted in an imminent (fast) engine icing event. The calculated wet bulb temperature based on the total temperature is shown in (a) and the static temperatures are illustrated in (b). 
Test Data Points Resulting in a Gradual Engine Icing Event.

Figures $8 \mathrm{a}$ and $8 \mathrm{~b}$ show the flow analysis results of the test data points that resulted in a gradual (slow) engine icing event. The figures illustrate the stream wise distribution of wet bulb temperature based on the total and static temperature (Figures $8 \mathrm{a}, 8 \mathrm{~b}$ respectively), as well as the ice particle melt ratio. At the data points where engine icing events were gradual, illustrated in Figure 8a, 8b, the wet bulb temperatures based on the local value of total temperature in the low pressure compressor Targeted Area was in a range of $13 \mathrm{R}$, with an average value being $13 \mathrm{R}$ above freezing. The wet bulb temperature based on the calculated local static temperature had a range of $14 \mathrm{R}$, with an average value of $2 \mathrm{R}$ above freezing. The local static temperature affects the melt ratio of the ice particle. The existence and the percentage of liquid water due to heating by the air appeared to have an effect on the rate of ice accretion. In the imminent icing event cases, the ice particle melt ratio due to heating by the air at the tandem stator trailing edge was an average of $15 \%$, with a range of $0 \%-55 \%$. As in the previous imminent icing event cases, the flow analyses indicate that the ice crystals partially melt due to heating from the air, producing a non-zero ice particle melt ratio in the targeted area of the exit guide vane for most of the test data points. It is possible that the other sources of heat that were not considered in this analysis provided the source of liquid water necessary for accretion, since the current analysis shows that some cases had zero melt ratio due to heating from the air, yet the engine eventually experienced an icing event, albeit slowly.

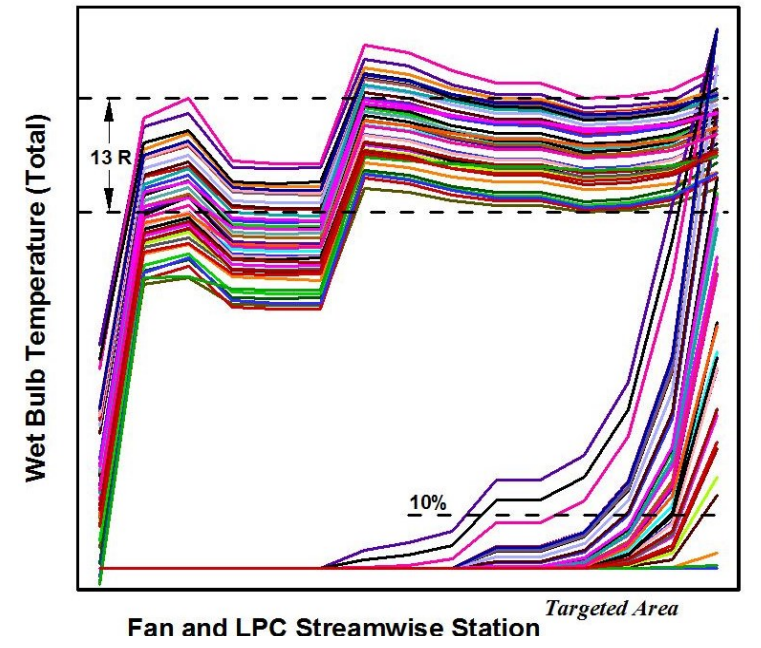

a)
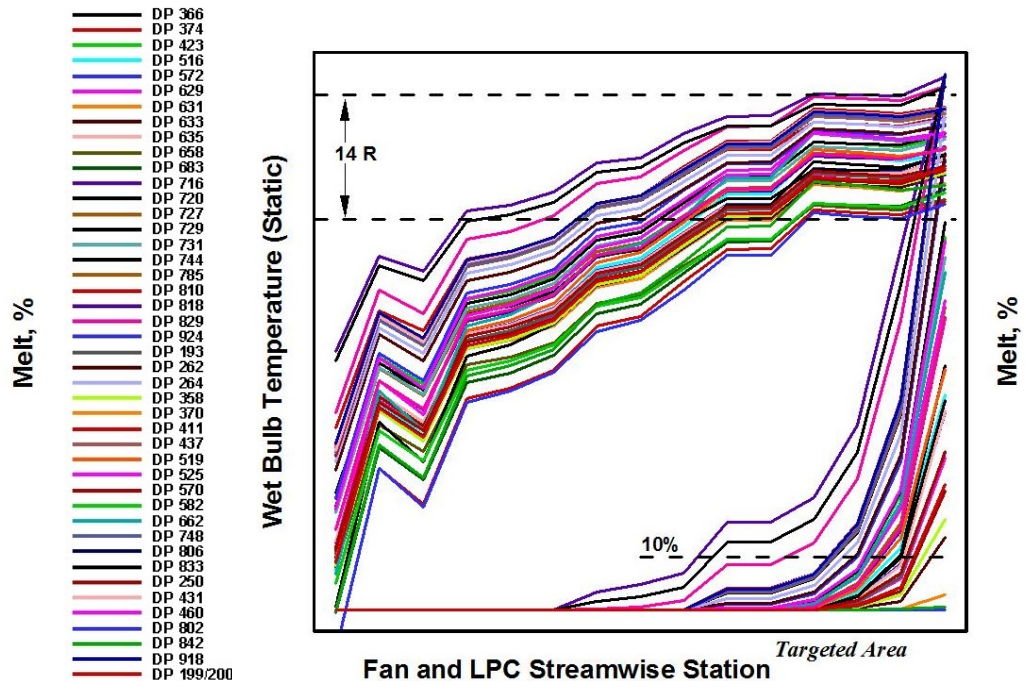

b)

Figure 8: Flow analysis of the fan-core and LPC stage at the test data points which resulted in gradual (slow) engine icing events. The calculated wet bulb temperature based on the total temperature is shown in (a) and the static temperatures are illustrated in (b).

Test Data Points Resulting in No Engine Icing Events.

Figures $9 \mathrm{a}$ and $9 \mathrm{~b}$ show the flow analysis results of the test data points that resulted in no engine icing events. The figures illustrate the stream wise distribution of wet bulb temperature based on the total and static temperature (Figures $9 \mathrm{a}, 9 \mathrm{~b}$ respectively), as well as the ice particle melt ratio. At the data points where the engine did not experience any icing events, illustrated in Figure 9a and 9b, the wet bulb temperatures based on the local value of total temperature in the low pressure compressor Targeted Area was in the range of $18 \mathrm{R}$, with an average value being $18 \mathrm{R}$ above freezing. Note that the average value is $5 \mathrm{R}$ above the wet bulb temperature calculated in the imminent and the gradual engine icing event cases. The wet bulb temperature based on the calculated local static temperature had a range of 17 $\mathrm{R}$, with an average value of $6 \mathrm{R}$ above freezing. In the no icing event cases, the ice particle melt ratio due to heating by the air at the tandem stator trailing edge was an average of $35 \%$, with a range of $0 \%-45 \%$. This is a higher average melt ratio than that seen in the previous two cases where engine icing events occurred. 


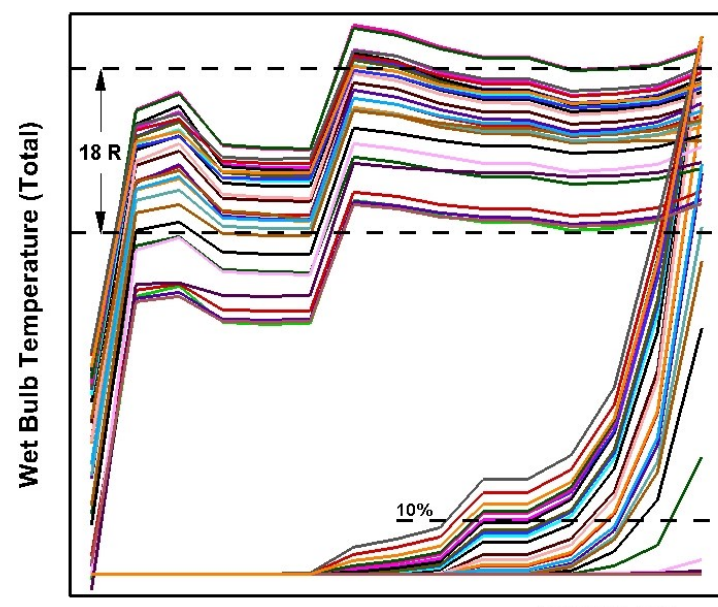

Fan and LPC Streamwise Station

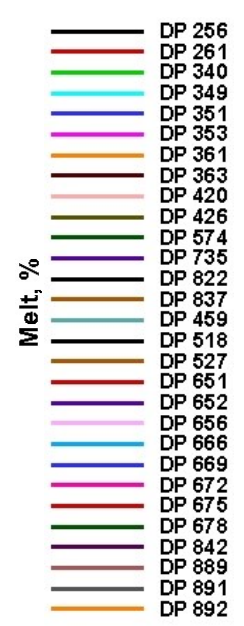

b)

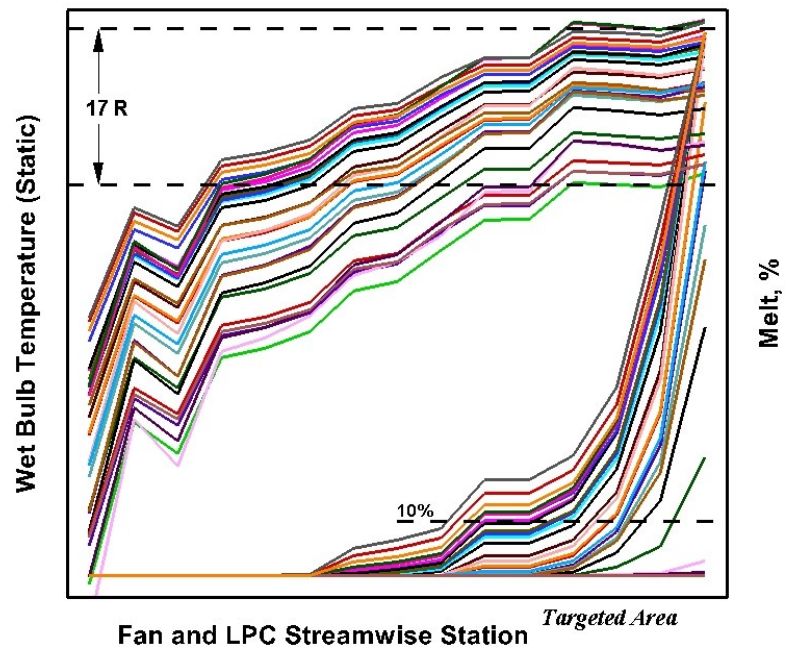

Fan and LPC Streamwise Station

a)

Figure 9: Flow analysis of the fan-core and LPC stage at the test data points which resulted in no engine icing events. The calculated wet bulb temperature based on the total temperature is shown in (a) and the static temperatures are illustrated in (b).

The simulations in this study does not account for phenomena such as the effects of slushy ice formation, ice shedding, and erosion. As the test data showed (Reference 12), in several cases the EGV thermocouple readings indicated evidence of ice accretion and ice shedding, yet often resulted in no engine icing event.

Fan-Core and LPC Characteristic Map, with all the Data Points.

Figure 10 shows the pressure ratio versus corrected flow and percent of design corrected speed characteristic map of the fan-core and LPC that was generated with the compressor flow analysis code. All fan-core and LPC operating points were superimposed on this characteristic map. Note that the characteristic map, as well as the data points, represents the nominal compressor performance prior to initiation of the ice cloud and therefore do not include the effects of ice accretion.

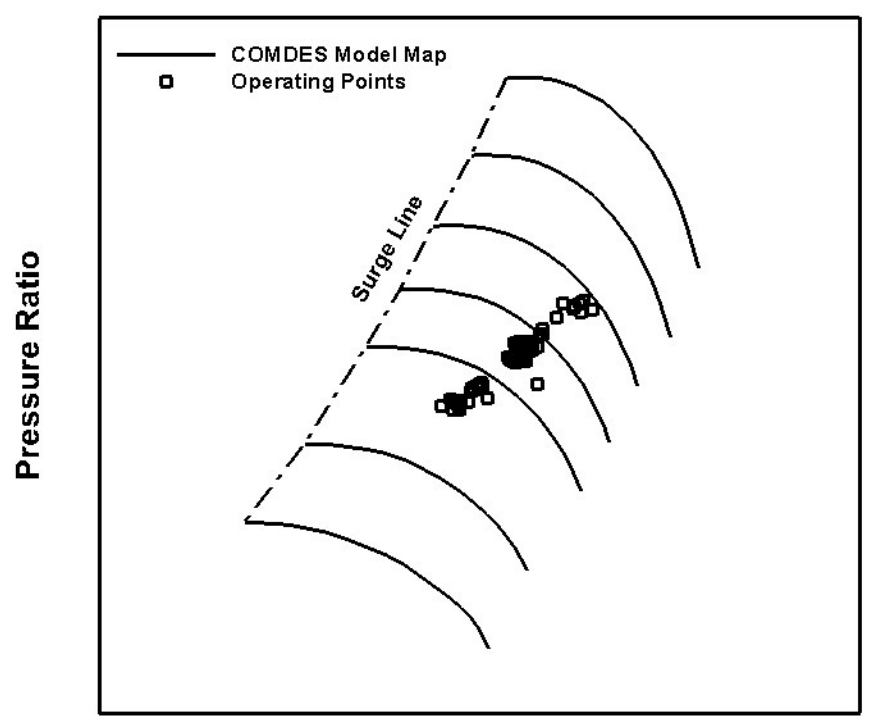

Flow Rate, corrected

Figure 10: The PSL test data operating points superimposed onto the fan-core and LPC characteristic performance map. These points represent all the PSL data points that are shown in Figures 7, 8, and 9. 
Figures $11 \mathrm{a}$ and $11 \mathrm{~b}$ illustrate the variation in calculated air static pressure and temperature in the tandem stator EGV (targeted area), at the test data points that have experienced imminent icing events. These test data point numbers are listed in the legend of Figure 7. One of the imminent icing event test data points (940), that resulted in a full engine roll back, was analyzed in detail to estimate the performance deterioration caused by blockage due to accretion (Reference 13).

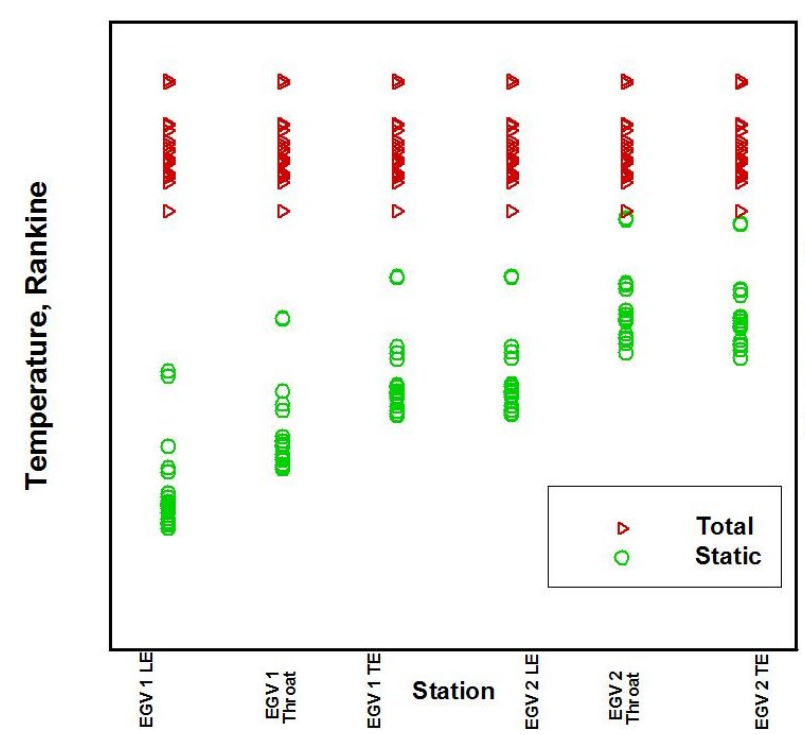

a)

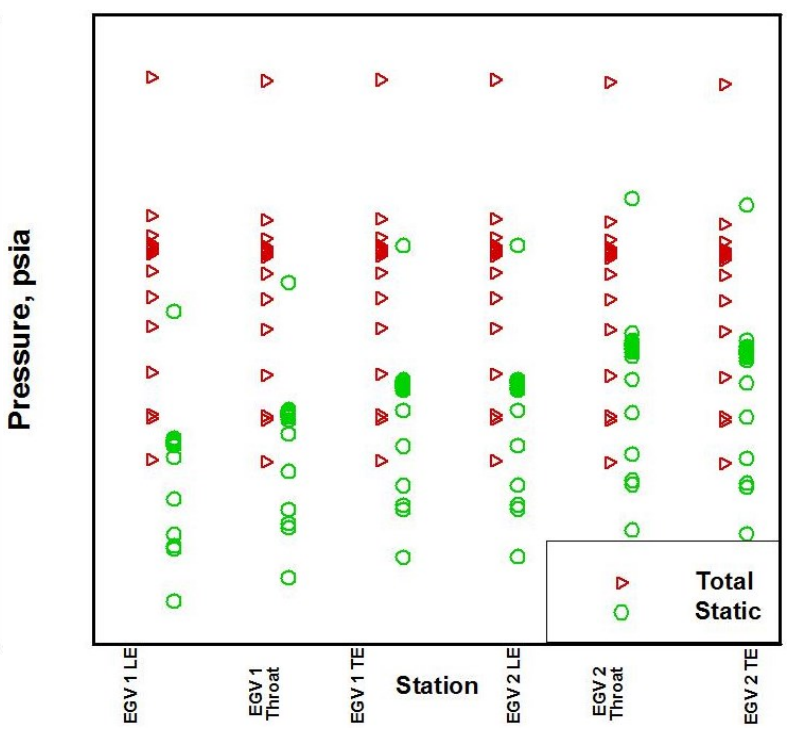

b)

Figure 11. The air temperatures (a) and pressures (b) at the EGV tandem stator 1 and 2 leading and trailing edges, as calculated by the computer model, for engine data points that experienced imminent (fast) ice accretion rates.

The range of air temperature and pressure variation through the EGV illustrated in Figures 11a and 11b are summarized in Table I.

Table I - Range of air temperature and pressure variation through the EGV for engine data points that experienced imminent (fast) ice accretion rates.

\begin{tabular}{|c|c|c|c|}
\hline & $\begin{array}{l}\text { EGV1 } \\
\text { Range }\end{array}$ & $\begin{array}{ll}\text { EGV2 } & \text { TE } \\
\text { Range } & \end{array}$ & $\begin{array}{l}\text { Total EGV 1, } 2 \\
\text { Range }\end{array}$ \\
\hline Total Temperature, $\mathbf{R}$ & 14.6 & 14.6 & 14.6 \\
\hline Static Temperature, $\mathbf{R}$ & $\mathbf{1 7 . 5}$ & 15.0 & 34.0 \\
\hline Total Pressure, psia & 3.9 & 3.9 & 4.0 \\
\hline Static Pressure, psia & 3.0 & 3.4 & 4.1 \\
\hline
\end{tabular}

\section{Comparison of Measured Engine Data and Engine System Model.}

There was a limited amount of standard instrumentation on the engine that was tested in the PSL measuring the total air flow, fuel flow, high pressure compressor exit pressure, and temperature, high pressure turbine (HPT) exit temperature. For each PSL data point, the CD engine system model also produced estimates of these parameters, as outlined in the computational process shown in Figure 3. The results of the CD system model were compared to the values measured in the PSL test, and the relative agreements in terms of percent difference are shown in Figures 12a $-12 \mathrm{j}$. Figures $12 \mathrm{a}, \mathrm{c}, \mathrm{e}, \mathrm{g}$, i show the difference relative to altitude, while Figures $12 \mathrm{~b}, \mathrm{~d}, \mathrm{f}, \mathrm{h}, \mathrm{j}$ show the difference relative to Escort data point number, which represent the test data points in chronological order. 

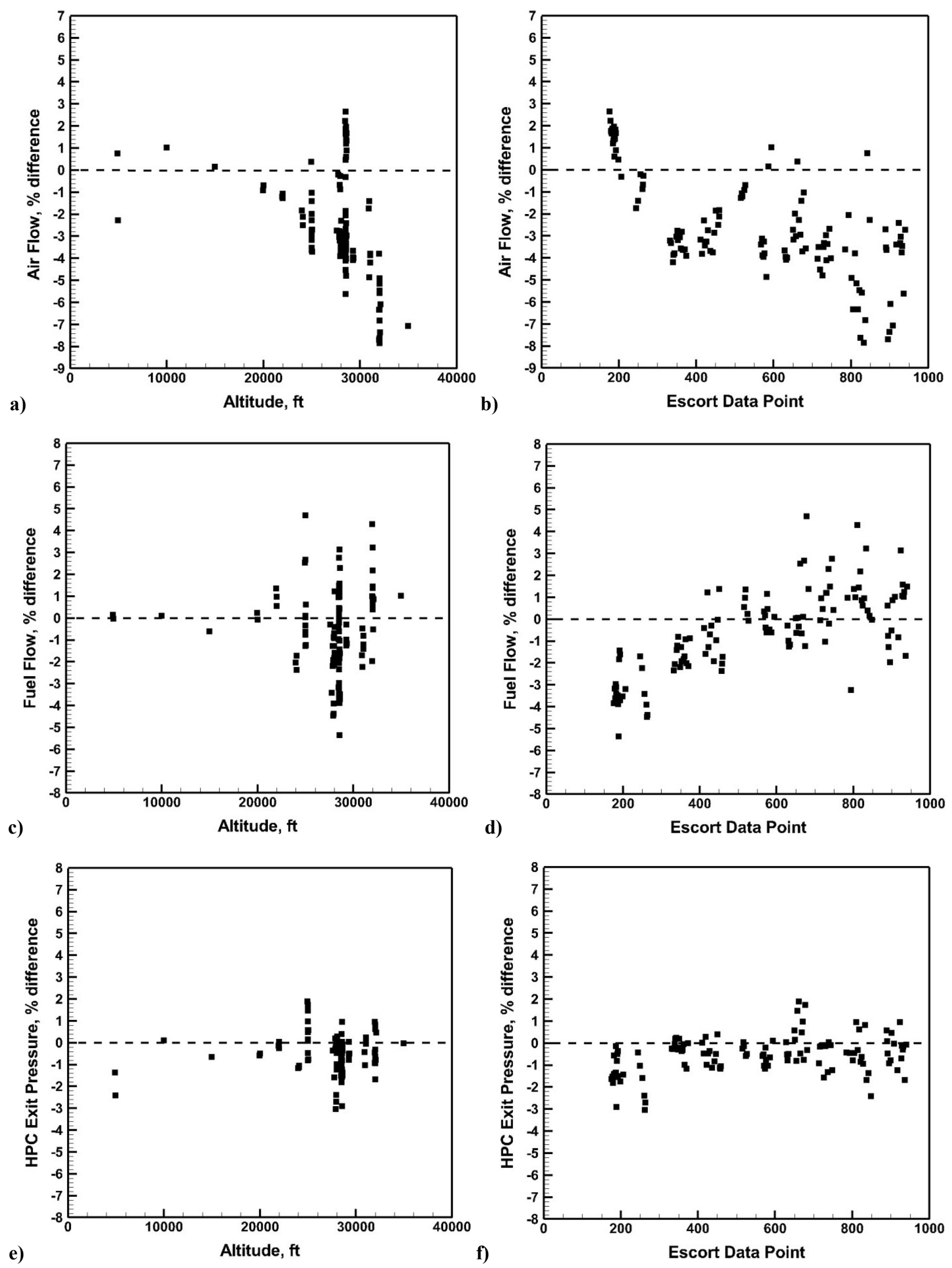

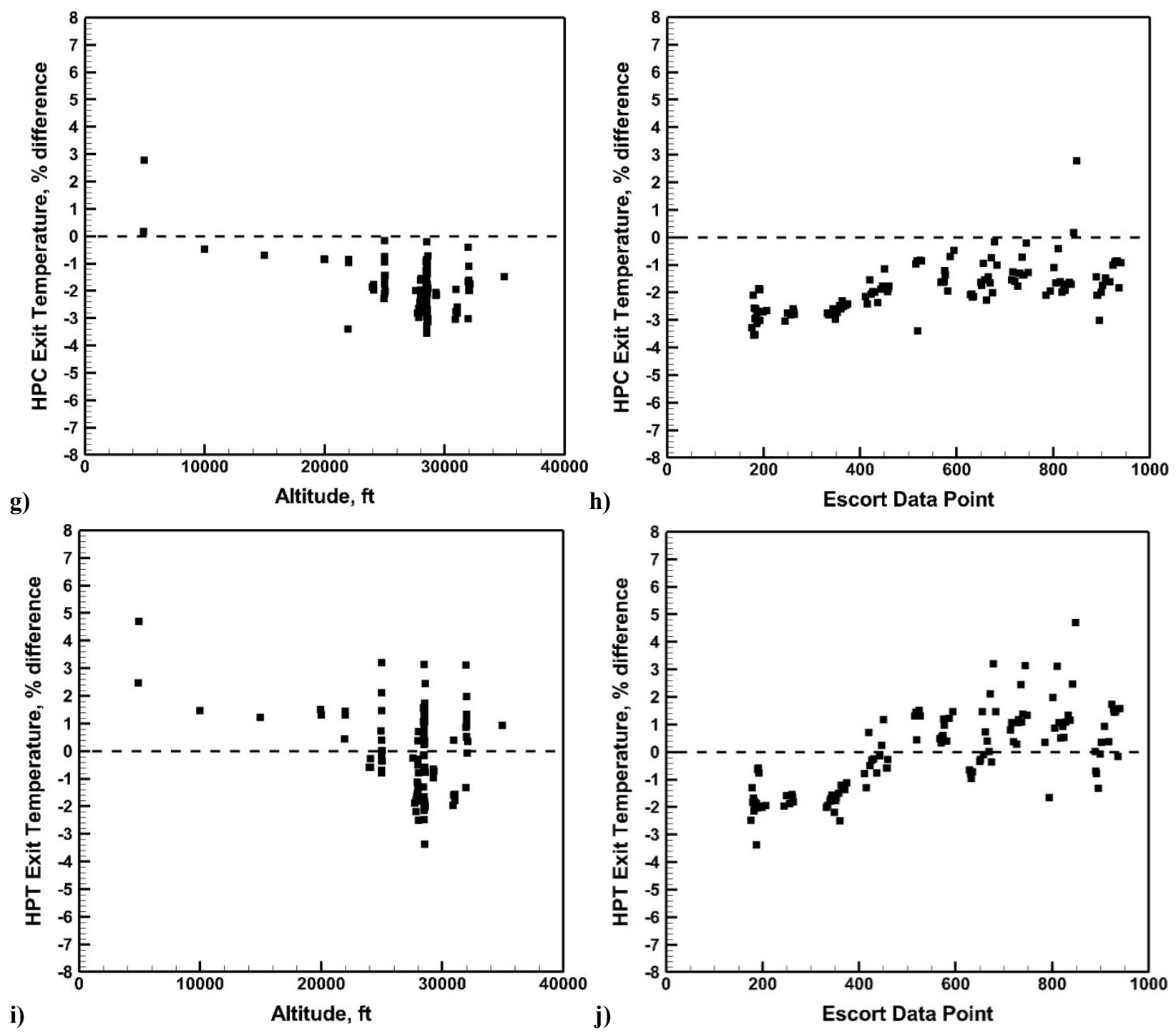

Figure 12: The percent difference between the measured data in the PSL and the values calculated with the CD engine system model (air flow, fuel flow, HPC exit pressure, HPC exit temperature, and HPT exit temperature) are shown vs. altitude (a, c, e, g, i) and vs. Escort data point number (b, d, f, h, j).

In an effort to understand the wide range of differences in air flow, fuel flow, HPC exit pressure, HPC exit temperature, and HPT exit temperature, as noted in Figures $12 \mathrm{a}-\mathrm{j}$, the three specific types of engine test data points (imminent, gradual, and no engine icing event occurred), were isolated to determine if the percent differences between the system model and the test data could be attributed to the type of engine icing event. However, there was no correlation. Hence, the range of wet bulb temperature for the imminent (fast), the gradual (slow), and the no engine icing events as illustrated in Figures 7a,b; 8a,b; and 9a,b cannot be attributed to the differences noted in Figures 12a - 12j. The above differences between measured and calculated show a trend with respect to time, or Escort data point number. The measured air flow in comparison to the CD engine system model calculated air flow decreased with Escort data point number, that is, with calendar time, as can be seen in Fig 12b. The measured fuel flow in comparison to the CD engine system model calculated fuel flow increased with Escort data point number, as can be seen in Fig 12d. The measured HPC exit pressure in comparison to the CD engine system model calculated HPC exit pressure showed no trend with Escort data point number, as can be seen in Fig 12f. The measured HPC exit temperature in comparison to the CD engine system model calculated HPC exit temperature increased slightly with Escort data point number, as can be seen in Fig 12h. The measured HPT exit temperature in comparison to the CD engine system model calculated HPT exit temperature increased with Escort data point number, as can be seen in Fig $12 \mathrm{j}$. Post-test inspection of the engine showed noticeable deposits of minerals on the blade surfaces, which might explain these trends. The differences 
between measured and calculated engine parameters indicate the uncertainty between the PSL test data and the analyses with the system model of the thermodynamic cycle. The total range of percent difference between the measured data and the values calculated with the CD engine system model for air flow, fuel flow, HPC exit pressure, HPC exit temperature, and HPT exit temperature, are summarized in Table II.

Table II - Differences between measured and calculated engine parameters.

\begin{tabular}{|l|l|l|l|l|l|}
\hline & Air flow & Fuel Flow & HPC Exit Press. & HPC Exit Temp. & HPT Exit Temp. \\
\hline Difference, \% & $\mathbf{1 1}$ & $\mathbf{1 0}$ & $\mathbf{5}$ & $\mathbf{7}$ & $\mathbf{8}$ \\
\hline Range, $\%$ & $\mathbf{- 8}$ to +3 & $\mathbf{- 5}$ to +5 & $-\mathbf{3}$ to $+\mathbf{2}$ & $-\mathbf{4}$ to +3 & $-\mathbf{3}$ to +5 \\
\hline Figure 12 & a, b & c,, $\mathrm{d}$ & $\mathrm{e}, \mathrm{f}$ & $\mathrm{g}, \mathrm{h}$ & $\mathrm{i}, \mathrm{j}$ \\
\hline
\end{tabular}

\section{Summary and Conclusion}

A turbofan engine known to have experienced an icing event at high altitudes and operating conditions during flight through convective ice crystal clouds was tested in the NASA Propulsion Systems Laboratory (PSL) simulated altitude engine test facility. The PSL facility has been fitted with spray bars to simulate ice crystal cloud. Engine icing events were successfully duplicated in the PSL facility at the same simulated altitudes at which icing events were encountered during flight with this engine. The current study focused on the thermodynamic cycle and flow analysis of all the engine test data taken in the PSL. The engine test data was categorized into three specific types of data points: those that resulted in an imminent icing event, those that resulted in a gradual engine icing event, and those data points which did not result in an engine icing event. The analysis tools utilized are an engine thermodynamic system model and a mean compressor flow analysis code. The compressor flow analysis code was executed to determine values for wet bulb temperature, and melt ratio through the fan-core and LPC flow path for all the data in the three specific types of test data points.

Although the current analyses resulted in a wide range of values of wet bulb temperature and melt ratio, the average values appeared to have some effect on whether an imminent (fast) icing event, gradual (slow) icing event, or no icing event would occur:

Imminent Icing event: The calculated average wet bulb temperature based on total temperature in the targeted area was $13 \mathrm{R}$ above freezing, with a range of $7 \mathrm{R}$. The average wet bulb temperature based on static in the targeted area was $2 \mathrm{R}$ above freezing, with a range of $9 \mathrm{R}$. while the average melt ratio was on the order of $12 \%$, with a range of $2 \%$ to $40 \%$.

Gradual Icing Event: The average wet bulb temperature based on total in the targeted area was $13 \mathrm{R}$ above freezing, with a range of $13 \mathrm{R}$. The average wet bulb temperature based on static in the targeted area was $2 \mathrm{R}$ above freezing, which is the same as that of the imminent engine icing event cases, but with a significantly broader range of $14 \mathrm{R}$. The average melt ratio was on the order of $15 \%$, with a range from $0 \%$ to $55 \%$. Since there was no difference between the average wet bulb temperatures for the imminent and gradual engine icing events, other factors likely influenced the elapsed time in which the icing event takes place, which were not modeled in this study.

No Icing Event: The average wet bulb temperature based on total in the targeted area was $5 \mathrm{R}$ higher than calculated in the imminent and gradual icing event cases, with a range of $18 \mathrm{R}$. The average wet bulb temperature in the targeted area based on static was $6 \mathrm{R}$ above freezing, with a range of $17 \mathrm{R}$. The average melt ratio was on the order of $35 \%$, with a range, from $0 \%$ to $45 \%$. Based on this analysis, it appears that the test data with no icing events has some correlation to the wet bulb temperature and to the melt ratio, as the average values of these were notably higher than for the imminent and the gradual icing event cases.

The comparison of measured engine test data and engine parameters calculated by the CD system model resulted in differences on the order of $\pm 5 \%$, thereby a degree of uncertainty in the compressor flow analyses results including the calculations of wet bulb temperature and melt ratio. These differences might be partially responsible for the overlap in the wet bulb temperature and melt ratio ranges for the three specific types of test data points analyzed. 
Additionally, the development of more detailed models in the current compressor flow analysis such as the physics of ice accretion may help to better differentiate between the three specific types of test data points. More detailed engine test data of the fan-core flow path are required, as well as higher fidelity physics-based analyses, including models for ice particle break up due to impact, erosion and ice accretion, in order to improve the understanding of aerothermodynamic parameters that lead to ice accretion, ice growth rate and to subsequent engine icing events.

\section{References}

${ }^{1}$ Mason, J. G., Chow, P., Fuleki, D. M., "Understanding Ice Crystal Accretion and Shedding Phenomenon in Jet Engines Using a Rig Test," GT2010-22550.

${ }^{2}$ Mason, J. G., Grzych, M., "The Challenges Identifying Weather Associated With Jet Engine Ice Crystal Icing,” SAE 2011-380094.

${ }^{3}$ Veres, J. P., Jorgenson, P. C. E., "Modeling Commercial Turbofan Engine Icing Risk with Ice Crystal Ingestion", AIAA 20132679.

${ }^{4}$ Veres, J. P., Jorgenson, P. C. E., Wright, W. B., Struk, P., “A Model to Assess the Risk of Ice Accretion due to Ice Crystal Ingestion in a Turbofan Engine and its Effects on Performance", AIAA 2012-3038.

${ }^{5}$ Jorgenson, P. C. E., Veres, J. P., Wright, W. B., May, R. D., "Engine Icing Modeling and Simulation (Part I): Ice Crystal Accretion on Compression System Components and Modeling its Effects on Engine Performance," SAE International, 2011-38-0025.

${ }^{6}$ Veres, J. P., “Axial and Centrifugal Compressor Mean Line Flow Analysis Method,” AIAA-2009-1641, NASA/TM-2009-215585. ${ }^{7}$ Wright, W. B., Potapczuk, M. G., and Levinson, L. H., "Comparison of LEWICE and GlennICE in the SLD Regime," AIAA2008-0439.

${ }^{8}$ Wright, W. B., Jorgenson, P. C. E., Veres, J. P., "Mixed Phase Modeling in GlennICE with Application to Engine Icing," AIAA2010-81093.

${ }^{9}$ Fowler, J. R., “GASPLUS User's Manual,” NASA LEW-15091, 1994.

${ }^{10}$ Struk, P., Currie, T., Wright, W. B., Tsao, J.-C., Broeren, A., Vargas, M., Knezevici, D., and Fuleki, D., "Fundamental Ice Crystal Accretion Physics Studies," SAE-11ICE-0034, 2011.

${ }^{11}$ Currie, T. C., Struk, P. M., Tsao, J.-C., Fuleki, D., Knezevici, D., "Fundamental Study of Mixed-Phase Icing with Application to Ice Crystal Accretion in Aircraft Jet Engines," AIAA-2012-3035.

${ }^{12}$ Oliver, M., et. al., "Validation Ice Crystal Icing Engine Test in the Propulsion Systems Laboratory at NASA Glenn Research Center", to be presented at the 2014 AIAA Conference in Atlanta, Georgia

${ }^{13}$ Jorgenson, P. C. E., Veres, J. P., Jones, S. M., "Modeling the Deterioration of Engine and Low Pressure Compressor Performance During a Roll Back Event due to Ice Accretion", to be presented at the 2014 Joint Propulsion Conference, Gas Turbine Engines, Engine Icing Session, in Cleveland, Ohio. 


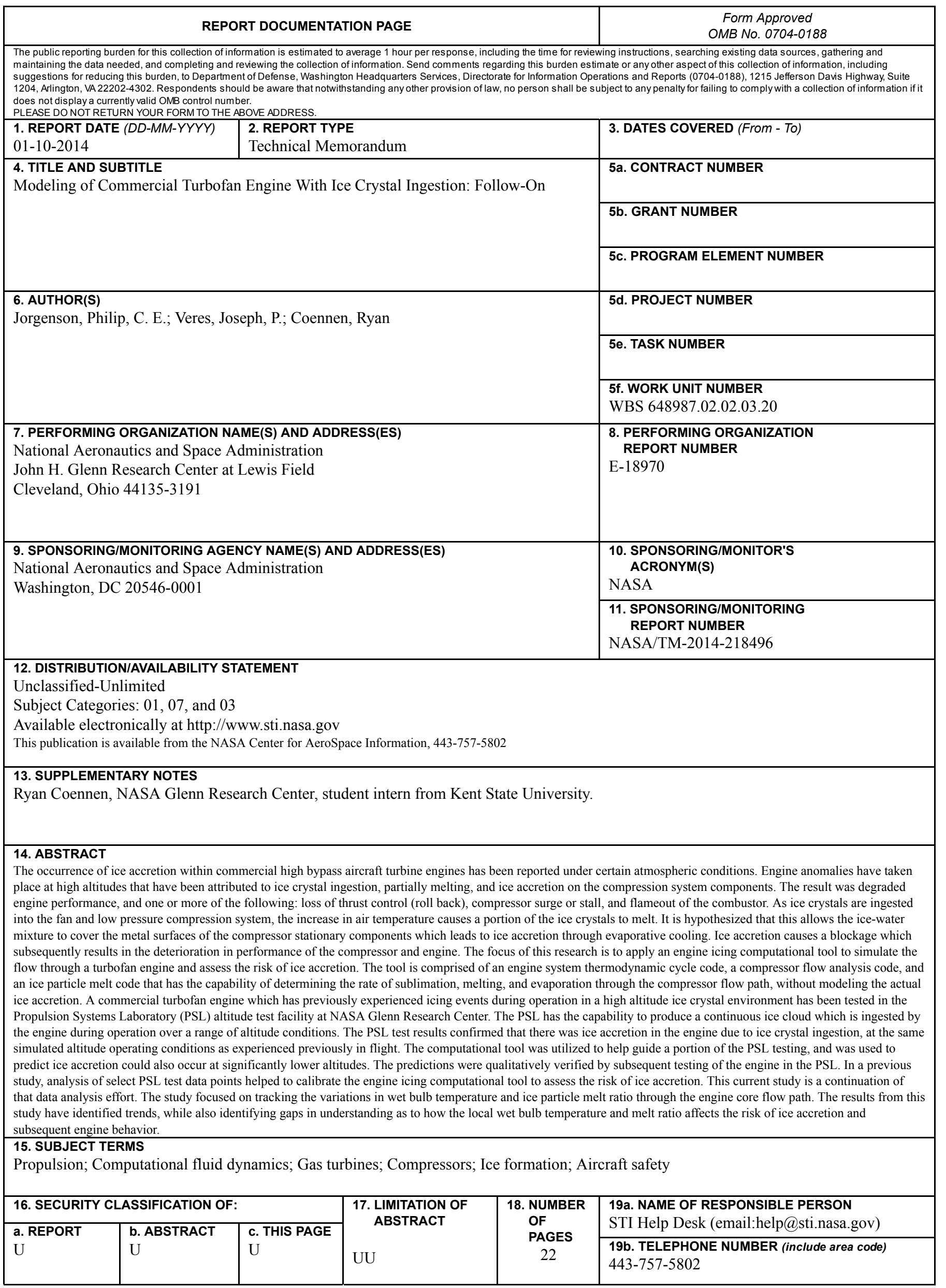



